* Corresponding author address: Department of Civil, Environmental, and Architectural Engineering, University of Colorado Boulder, Boulder, CO, USA; Tel: +1 (303) 492 4137;

Fax: +1 (303) 492 7317; E-mail: zhiyong.ren@colorado.edu

\title{
Microbial Fuel Cells and Osmotic Membrane Bioreactors Have Mutual Benefits for Wastewater Treatment and Energy Production
}

\author{
by \\ Dianxun Hou, Lu Lu, Zhiyong Jason Ren* \\ Department of Civil, Environmental, and Architectural Engineering, University of \\ Colorado Boulder, Boulder, CO, USA
}




\section{Abstract}

2 This study demonstrates that microbial fuel cells (MFCs) and osmotic membrane

3 bioreactors (OMBRs) can be mutually beneficial when integrated together for

4 wastewater treatment. When connecting MFCs with OMBRs, the solute buildup

5 increased conductivity and buffer capacity, which greatly increased MFC power density

6 from $3 \mathrm{~W} / \mathrm{m}^{3}$ up to $11.5 \mathrm{~W} / \mathrm{m}^{3}$. In turn, the MFCs conditioned and reduced sludge

7 production and therefore reduced forward osmosis (FO) membrane fouling. The MFC-

8 OMBR equipped with new thin-film composite (TFC) membrane showed excellent

9 organic (>95\%) and phosphorus removal (>99\%) and therefore maintained effluent

$10 \mathrm{SCOD}$ below $20 \mathrm{mg} / \mathrm{L}$. However, the nitrogen removal was limited due to the negative

11 surface charge of the thin-film composite membrane and solution chemistry, which led

12 to higher flux of ammonium toward the OMBR draw solution. Further studies are

13 needed to improve nitrogen removal, reduce fouling, and optimize system integration.

14

15 Keywords: forward osmosis, microbial fuel cell, thin-film composite membrane, osmotic 16 membrane bioreactor 


\section{Introduction}

2 Microbial fuel cells (MFCs) and osmotic membrane bioreactors (OMBRs) are two

3 emerging technologies for sustainable wastewater treatment. While most studies focus

4 on individual technology development, we hypothesize that these two processes can be

5 mutually beneficial. MFCs use electrochemically active microorganisms to produce

6 direct current from wastewater with less sludge production, but the current density is low

7 from municipal wastewater due to its low conductivity and buffer capacity.(Nam et al.,

8 2010; Wang and Ren, 2013; Logan et al., 2015; Zhang et al., 2015) Another challenge

9 of MFCs is that the effluent quality (e.g., chemical oxygen demand (COD) and turbidity)

10 generally cannot meet the discharge standard and therefore requires post-

11 treatment.(Logan et al., 2015; Zhang et al., 2015) Membrane processes such as

12 ultrafiltration (UF), microfiltration (MF), and FO have been incorporated into MFCs, and

13 the effluent quality has been significantly improved.(Wang et al., 2011; Ge et al., 2013a;

14 Ren et al., 2014; Tian et al., 2014; Yuan and He, 2015; Zuo et al., 2015) Most previous

15 research focused on this effluent quality aspect with good success, but in this study we

16 hypothesize that the accumulation of $\mathrm{FO}$ solute (e.g., $\mathrm{NaCl}, \mathrm{PO}_{4}{ }^{3-}$ and $\mathrm{HCO}_{3}{ }^{-}$) similar to

17 high contaminants retention improves the solution salinity and buffer capacity and

18 therefore will improve MFC power production.

20 On the other hand, because MFCs remove organic matters with small biomass

21 accumulation, we anticipate that they may reduce FO membrane fouling as pre-

22 treatment by improving the mixed liquor properties.(Tian et al., 2014) Forward osmosis

23 (FO) is an osmotically-driven membrane process where water flows from a low-salinity 
1 feed solution (FS) to a high-salinity draw solution (DS) through a semi-permeable

2 membrane.(Cath et al., 2006; Achilli et al., 2009; Lay et al., 2010; Chen et al., 2014;

3 Holloway et al., 2014; Gu et al., 2015; Holloway et al., 2015) The non-porous FO

4 membrane with lower fouling propensity acts as a barrier to the contaminants so provide

5 a high-level wastewater treatment and reclamation.(Lay et al., 2010; Chen et al., 2014;

6 Holloway et al., 2014; Gu et al., 2015; Holloway et al., 2015) Although OMBRs are likely

7 to have lower fouling propensity compared to the conventional pressure-driven MBRs

8 with MF or UF membranes, fouling is still a major challenge where the concentrations of

9 foulants are high. (Lay et al., 2010; Chen et al., 2014; Holloway et al., 2014; Gu et al.,

10 2015; Holloway et al., 2015) Another unknown factor is the FO membrane materials.

11 Most existing OMBR and/or osmotic microbial fuel cell (OsMFC) studies were

12 performed with cellulose triacetate (CTA) based FO membranes.(Achilli et al., 2009; Lay

13 et al., 2010; Zhang et al., 2011; Ge et al., 2013b; Chen et al., 2014). However, it was

14 shown that CTA membranes are vulnerable to hydrolysis and biological

15 degradation.(Geise et al., 2010; Chen et al., 2014) Thus, in this study we investigated

16 the thin film composite (TFC) polyamide FO membranes, which has higher water flux,

17 better solute rejection, and biodegradation resistance.(Yip et al., 2010; Wei et al., 2011)

18 Despite the great potential of TFC membranes for FO applications, their performance

19 and fouling behavior in MBRs are rarely reported in the literature.

20

21 In this study, we investigated the mutual benefits between MFCs and OMBRs with new

22 TFC FO membrane for low strength wastewater treatment. The central hypothesis is

23 that by connecting MFC with OMBR, the accumulated FO solute increases solution 
1 conductivity and alkalinity and therefore improve ion transfer and MFC power output.

2 The MFCs pretreat the wastewater with reduced sludge production, so it reduces

3 membrane fouling in OMBRs. We investigated the MFC-OMBR system performance

4 under different conditions in terms of TFC FO membrane flux level, solute transport, and

5 nutrient removal, as well as organic removal and power production from MFCs. We also

6 characterized TFC membrane fouling behaviors in the MFC-OMBR system and

7 analyzed the potential mechanisms of nutrient transfer.

9 2. Material and methods

$10 \quad 2.1$ Membranes and Chemicals

11 A commercial TFC FO membrane (Hydration Technology Innovations, Albany, OR) was

12 used in this study. The membrane has a water permeability of $7.49 \times 10^{-12} \mathrm{~m} / \mathrm{s}$. Pa, a

$13 \mathrm{NaCl}$ permeability of $7.40 \times 10^{-8} \mathrm{~m} / \mathrm{s}$, and a structure parameter of $0.70 \mathrm{~mm}$.(Coday et al.,

14 2015; Wang et al., 2016) Membrane coupons were soaked in MilliQ water (18.2 M $2 . \mathrm{cm}$ )

15 at room temperature for over $24 \mathrm{~h}$ before use.(She et al., 2013a; Zhang et al., 2014)

16 Glucose-based defined medium was used as the synthetic feed wastewater, so

17 degradation and mass transfer mechanisms can be understood. (Huggins et al., 2013;

18 Gu et al., 2015; Lu et al., 2015) The medium contained (mg/L): glucose, 250; yeast

19 extract, $100 ; \mathrm{NaCl}, 400 ; \mathrm{NaHCO}_{3}, 150 ; \mathrm{NH}_{4} \mathrm{Cl}, 80 ; \mathrm{KH}_{2} \mathrm{PO}_{4}, 50 ; \mathrm{MgCl}_{2} \cdot 6 \mathrm{H}_{2} \mathrm{O}, 5$; and

$20 \mathrm{CaCl}_{2}, 10$. The total soluble chemical oxygen demand (sCOD), $\mathrm{NH}_{3}-\mathrm{N}, \mathrm{PO}_{4}-\mathrm{P}$, electric

21 conductivity and $\mathrm{pH}$ of the feed solution were $400 \pm 10 \mathrm{mg} / \mathrm{L}, 21.6 \pm 0.5 \mathrm{mg} / \mathrm{L}, 13.0 \pm$

$220.2 \mathrm{mg} / \mathrm{L}, 1.20 \pm 0.05 \mathrm{mS} / \mathrm{cm}$ and $7.25 \pm 0.05$, respectively. 


\section{$1 \quad 2.2$ Reactor Configuration and Operation}

2 The schematic diagram of the two-stage MFC-OMBR system is shown in Figure 1. The

3 system consists of two parallel MFCs and one OMBR, which are hydraulically

4 connected in series. The single-chamber MFCs used carbon-brush anodes and air-

5 cathodes. The volume of the MFCs was $110-120 \mathrm{~mL}$, respectively, due to the size

6 differences of the anode brushes. The MFCs were inoculated with the anaerobic

7 digested sludge collected from Boulder Wastewater Treatment Plant and fed with the

8 synthetic wastewater. In the OMBR, a tubular membrane module (effective membrane

9 area, $A_{m}: 81 \mathrm{~cm}^{2}$ ) with active layer facing feed orientation was fully submerged into a

10 bioreactor (effective volume, $V_{R}: 1.5 \mathrm{~L}$ ). A magnetic stirrer bar was used to mix the

11 solution in the OMBR at a speed of $400 \mathrm{rpm}$. In order to study the performance and

12 fouling behavior of the MFC-OMBR system, different operation practices were

13 conducted (Table 1). In Run 1, fresh medium was used after system inoculation, and no

14 membrane cleaning was performed during the run. In Run 2, the same operation was

15 performed, but the membrane was chemically cleaned each day to investigate the

16 difference in membrane fouling behavior. The chemical cleaning procedure included 30

17 min alkaline $(0.2 \% \mathrm{NaOH} / 0.2 \%$ EDTA) wash followed by 30 min acid (2\% citric acid)

18 wash.(Wang et al., 2015) In Run 3, similar operation was used as Run 1, except 2000

$19 \mathrm{mg}$ total suspended solids (TSS)/L anaerobic sludge was added together with the

20 medium into the MFC-OMBR system to understand if MFCs could serve as a pre-

21 treatment to reduce membrane fouling. The performance under these operations was

22 compared with a control conventional anaerobic OMBR (Run 4, 2000 mgTSS/L

23 anaerobic sludge) without MFCs. Each run was performed three cycles. In Run 1-3, the 
1 same membrane module was used and chemical cleaning was performed to restore the

2 membrane flux after each cycle; however, due to membrane damage in Run 3, a fresh

3 membrane module was employed in Run 4. All reactors were maintained at anaerobic

4 condition and $28 \pm 0.5^{\circ} \mathrm{C}$.

[Figure 1]

6 During operation, the solution volume of the MFC-OMBR system was monitored by a

7 water level sensor. The flow was controlled by the volume of permeate extracted from

8 the OMBR. When the water level of the OMBR dropped below the designated value,

9 fresh feed wastewater converged with the same amount of bulk solution from the OMBR

10 (Recycle Ratio $=100 \%)$ was firstly transferred into the two MFCs in parallel then into the

11 OMBR using a peristaltic pump. Conductivity, temperature, $\mathrm{pH}$, oxidation-reduction

12 potential (ORP) values in the OMBR were monitored and logged using LabVIEW. In the

13 meanwhile, draw solution (DS, $0.5 \mathrm{M} \mathrm{NaCl}$ ) was recirculated at a cross flow velocity of

$148.3 \mathrm{~cm} / \mathrm{s}$ (equivalent to a flow rate of $230 \mathrm{~mL} / \mathrm{min}$ ). The concentration of $\mathrm{DS}$ was

15 monitored by conductivity measurements and maintained constant through dosing a 5

$16 \mathrm{M} \mathrm{NaCl}$ stock solution. The water flux was determined gravimetrically by weighing the

17 mass of permeate water collected at predetermined time intervals with a digital balance

18 (VWR, Radnor, PA). The FO membrane rejection rate $\left(R_{m}\right)$ and the overall removal

19 efficiency $\left(\eta_{R}\right)$ of the MFC-OMBR system were calculated using Eq. (1) and Eq. (2), 20 respectively.

21

$$
\begin{aligned}
& R_{m}=1-\frac{C_{P}}{C_{R}} \approx 1-\frac{C_{D S}}{C_{R}} f_{D} \\
& \eta_{R}=1-\frac{C_{D S} V_{D S}}{C_{F S} V_{F S}-V_{R} \Delta C_{R}}
\end{aligned}
$$


1 where $C_{P}, C_{R}, C_{D S}$ and $C_{F S}$ are the solutes and/or contaminants concentrations in the

2 permeate, bulk reactor, draw solution and feed solution, respectively; and $V_{D S}$ and $V_{F S}$,

3 are the volume of draw solution and feed solution; $\Delta C_{R}$ is the concentration change of

4 solutes and/or contaminants in the bulk reactor; $f_{D}$ is the concentration factor, i.e., the

5 ratio of $C_{D S} / C_{P}, \sim 1.11$ in this experiment. Detailed descriptions of of $R_{m}$ and $\eta_{R}$ can be

6 found elsewhere.(Gu et al., 2015)

\subsection{Water and Solute Flux Modeling}

9 In order to simulate water flux and solute accumulation in OMBR, a water flux model

10 accounting concentration polarization was developed and given by:

$$
J_{w}=K_{m} \ln \frac{\pi_{D}+\frac{B}{A}}{\pi_{F}+\frac{J_{W}}{A}+\frac{B}{A}}
$$

12 where, $K_{m}$ is the mass transfer coefficient, $\Pi_{D}$ osmotic pressure of draw solution, $\pi_{F}$

13 feed solution osmotic pressure, $A$ membrane water permeability, and $B$ solute

14 permeability. (She et al., 2012; She et al., 2013a)

16 Based on classic solution-diffusion theory, the reverse solute flux in FO process can

17 be determined by:

$$
\frac{J_{S_{S} D S}}{J_{W}}=\frac{B}{A \beta R T}
$$

19 where $J_{S_{-} D S}$ is the reverse solute flux from draw solution, $\beta$ the van Hoff coefficient for

$20 \mathrm{NaCl}, R$ the universal gas constant, and $T$ temperature in Kelvin (Phillip et al., 2010;

21 Tang et al., 2010; She et al., 2012; She et al., 2013b). The values of constants and

22 modeling parameters can be found in Table S2 in Supporting Information. Moreover,

23 the accumulated solute flux from wastewater $\left(J_{S_{-} F S}\right)$ can be described as: 


$$
\frac{J_{S} F S}{J_{w}}=C_{F S}
$$

2 Thus, the theoretical ratio of the accumulated solute flux from wastewater to the total

3 solute accumulation $\left(\eta_{s}=83.3 \%\right.$ in this study) can be determined using:

$$
\eta_{S}=\frac{J_{S_{-} F S}}{J_{S_{-} F S}+J_{S_{-} D S}}
$$

5 Experimentally, the contributions of solutes from wastewater to the total solute 6 accumulation $\left(\eta_{s}\right)$ in OMBR can be estimated using:

$$
\eta_{s}{ }^{\prime}=\frac{E C_{0}\left(\frac{\int J_{w} A_{m} d t}{V_{R}}+1\right)}{E C_{t}+\sum_{1}^{t} \frac{V_{S}}{V_{R}}\left(E C_{t}-E C_{0}\right)}
$$
where $E C_{0}$ is the solution conductivity of fresh wastewater, $\int J_{w} A_{m} d t$ the cumulative volume of water transport to the draw solution from the OMBR bulk solution at time $\mathrm{t}, V_{R}$

10 the OMBR reactor volume, $E C_{t}$ the solution conductivity in OMBR at time t, and $V_{S}$ the 11 sampling volume at time $\mathrm{t}$.

\subsection{Analyses}

14 All samples for SCOD, $\mathrm{N}$ and $\mathrm{P}$ measurements were filtered through $0.45 \mu \mathrm{m}$ cellulose

15 membranes (Millipore), and the sludge was used for TSS measurements. SCOD and

16 TSS were measured according to standard methods described in detail by American

17 Public Health Association.(APHA, 1998) $\mathrm{NH}_{3}-\mathrm{N}$ (TNT 832/831/830) and $\mathrm{PO}_{4}-\mathrm{P}$ (TNT

18 846) were measured with $\mathrm{HACH}$ test tubes $(\mathrm{HACH}$, Loveland, $\mathrm{CO})$. All samples were

19 collected and analyzed in triplicate. It should be noted that the samples collected from

20 the MFC-OMBR system were replaced by the same amount of fresh wastewater. 
1 The voltage across an external resistor $(R, 10 \Omega)$ over the MFCs was recorded every 10

2 minutes using a data acquisition system (Keithley Instruments, Inc., OH). The current

3 was calculated by:

$$
I_{i}=\frac{U_{i}}{R}
$$

5 The overall Coulombic efficiency (CE) (\%) of the MFCs was calculated using:

$$
C E=\frac{\sum_{1}^{2}\left(\sum_{i=1}^{n} I_{i} t_{i}\right)}{F b \Delta S} M
$$

7 where $U_{i}$ is the output voltage of MFC at time $t_{i}, R$ the external resistance, $F$ Faraday's 8 constant (96485 C/mole), $b$ the number of moles of electrons produced per mol of COD

9 (4 $\mathrm{mol}$ of $\mathrm{e}^{-} / \mathrm{mol}$ of $\mathrm{COD}$ ), $\Delta S$ the removed substrate (mg COD), and $M$ the molecular 10 weight of oxygen (32 $\mathrm{g} / \mathrm{mol})$.(Luo et al., 2012b) Polarization curves were obtained by

11 linear sweep voltammetry (LSV) using a potentiostat (PC4/300, Gamry Instruments, NJ).

12 The scan rate of LSV was $0.1 \mathrm{mV} / \mathrm{s}$ with the anode as working electrode and the 13 cathode as counter and reference electrode.(Wang et al., 2012) Power density and

14 current density were normalized by the effective volume (Ge et al., 2014). Paired two15 sample t test was performed to study the significance of fouling mitigation and power 16 production improvement.

\section{Results and discussion}

\section{3.1. Salt Accumulation and Water Flux Change}

20 Figure 2 shows the time-course change of solution conductivity (Figure 2a) and water

21 flux (Figure 2b) in the OMBR during different operations. Though varied in different 22 conditions, the solution conductivity increased from $1.2 \pm 0.05$ up to $12.6 \pm 1.2 \mathrm{mS} / \mathrm{cm}$, 23 and the corresponding water flux decreased from $12.0 \pm 0.7$ to $2.0 \pm 0.2 \mathrm{LMH}$ in 9 days. 
1 The increase of solution conductivity was due to accumulation of solutes from wastewater (i.e., $\mathrm{NaCl}, \mathrm{NaHCO}_{3}, \mathrm{KH}_{2} \mathrm{PO}_{4}$ ) as well as the reversely diffused solutes (i.e., $\mathrm{NaCl}$ ) from DS into the OMBR. Previous modeling on OMBR solute accumulation using CTA membranes showed comparable contributions of these two mechanisms, (Xiao et al., 2011; Chen et al., 2014; Gu et al., 2015) but this study shows that the salts from wastewater influent was the major contributor $\left(\eta_{s}^{\prime}=82.1 \pm 4.0 \%\right)$ of the salinity build-up in the OMBR, indicating better solutes rejection of the TFC membrane than that of CTA membrane (Figure S2 in Supporting Information).

\subsection{Membrane Fouling Behavior and the Benefits of MFCs}

Figure $2 \mathrm{~b}$ shows the water flux changes under different conditions. It can be seen that Run 2 with daily membrane cleaning showed almost the same profile as the modeled water flux, which simulated the flux under solute conductivity build-up without considering membrane fouling. This reveals that the water flux of the fouled membrane was almost fully recovered after chemical cleaning, and the water flux decline in Run 2 was mainly caused by the decrease of driving force across the membrane due to the salinity build-up in the bioreactor.

When no chemical cleaning was performed, as shown in Run 1, Run 3, and Run 4, membrane fouling led to more significant flux salvage, suggesting fouling mitigation is needed. This is different from the OMBRs with CTA membranes, where salt accumulation was the major contributor to flux decline other than membrane fouling (Chen et al., 2014; Gu et al., 2015). The high fouling property of TFC membrane might 
1 be due to the rougher surface and surface charge, which may promote divalent cation

2 (e.g., $\mathrm{Ca}^{2+}, \mathrm{Mg}^{2+}$ ) enhanced fouling.(Vrijenhoek et al., 2001; Mi and Elimelech, 2008; Mi

3 and Elimelech, 2010; Liu and Mi, 2012; Gu et al., 2013) Interestingly, although similar

4 flux declines were observed during the first 4 days, further flux drops in Run 1, 3, and 4

5 behaved differently. The flux of Run 1 stabilized around $4.0 \pm 0.5 \mathrm{LMH}$, but the flux of

6 Run 3 kept decrease till 3.0 $\pm 0.2 \mathrm{LMH}$, while the flux of Run 4 dropped even lower to

$7 \quad 2.0 \pm 0.2 \mathrm{LMH}$ in Day 9. These results indicate that lower sludge accumulation alleviated

8 membrane fouling, because Run 1 was not amended with extra sludge, and the TSS in

9 Run 1 was all below 350 mg/L. In comparison, both Run 3 and Run 4 showed greater

10 flux decline and more severe fouling due to addition of external sludge (TSS $=2000$

$11 \mathrm{mg} / \mathrm{L}$ ) (Figure S3 in Supporting Information). The less fouling property of Run 1 and Run

122 was also supported by the fact that almost full flux recovery $(97.3 \pm 0.7 \%)$ was obtained

13 each time after chemical cleaning. This recovery was much higher than the water flux

14 recovery ratio after Run 3 and Run 4 , which were $86.1 \pm 0.5 \%$ and $84.4 \pm 0.8 \%$,

15 respectively. It should be noted that the flux drop of Run 3 was lower than Run $4(P<$

16 0.05), which suggested that the MFCs served as a pre-treatment to improve sludge

17 property and reduced fouling potential. (Tian et al., 2014) It is acknowledged that the

18 benefit of MFCs to OMBR is not as substantial (though statistically significant, $P<0.05$ )

19 as hypothesized, partially due to the separate designs and operation of the two reactors.

20 Previous studies have used also MFCs for sludge reduction and power generation, and

21 results were positive in both MFC-alone operations and MFC-MBR combinations. (Su et

22 al., 2013; Tian et al., 2014) 


\subsection{MFC Power Production and the Benefits of OMBR}

4 Figure 3 compares the power production from the two MFCs operated in parallel in Run

51 (without cleaning) and Run 2 (with cleaning). For both MFCs, the power outputs

6 increased in the first 4 days, which directly correlated with increase in solution

7 conductivity shown in Figure 2 a as well as buffer capacity due to solute build-up (Figure

$8 \quad$ S4 in Supporting Information). Moreover, because Run 2 showed higher conductivity

9 and $\mathrm{pH}$ increase, the power outputs from both MFCs in Run 2 were also higher than the

10 outputs from Run $1(P<0.05)$. The highest power density accomplished by the MFC 1

11 and MFC 2 were $11.5 \pm 0.9 \mathrm{~W} / \mathrm{m}^{3}$ and $9.6 \pm 0.3 \mathrm{~W} / \mathrm{m}^{3}$, respectively. This demonstrates that

12 the OMBR maybe a better integration option than MF/UF membranes for MFCs as it

13 helps condition the solution for higher power output. Most MFC power outputs dropped

14 after 6 days especially for Run 2 with higher flux. This is mainly caused by the depletion

15 of substrates. As shown in Figure 4, the SCOD reading dropped to $\sim 100 \mathrm{mg} / \mathrm{L}$ after 4 16 days, which was a level reported not enough to support sustainable power 17 production.(Zhang et al., 2015)

19 The Coulombic efficiency increased from $3.3 \pm 0.8 \%$ up to $22.6 \pm 2.1 \%$ in Run 1 and from

$206.4 \pm 1.1 \%$ up to $15.7 \pm 2.2 \%$ in Run 2. Run 2 showed higher power production but lower

21 Coulombic efficiency than Run 1, which is believed due to the flux difference. Despite of

22 higher solutes accumulation and carbon source input, the higher shear stress caused by

23 higher flow rate in Run 2 may promote mass transfer in the MFCs thus improving 
1 current production.(Aaron et al., 2010) However, the carbon source competition

2 between the biomass in the OMBR (Figure S5 and S6 in Supporting Information) and

3 the anode biofilm may lead to reduction of Coulombic efficiency.(Zhang et al., 2015)

4 Moreover, it is expected that the recirculation ratio may play an important role through

5 controlling the balance between solution conductivity, buffer capacity and substrate

6 availability for the reactors. Research and modeling works on the effects of different

7 operational parameters are needed in future studies.

\section{[Figure 3]}

\section{3.4. Organics and Nutrients Removal}

12 Figure 4 shows the SCOD concentration changes in the MFC effluent, OMBR bulk

13 solution, and draw solution in Run 1 without membrane cleaning. It can be seen that the

14 SCOD in the MFC effluents as well as the bulk solution dropped very quickly from 400 to

$15 \sim 100 \mathrm{mg} / \mathrm{L}$ in 4 days, presumably due to the biological degradation in the MFC and

16 OMBR reactors. The biomass accumulation in the OMBR supports the hypothesis, and

17 the total suspended solid (TSS) production rates were $0.078 \pm 0.008 \mathrm{~g} / \mathrm{gCOD}$ and 0.074

$18 \pm 0.010 \mathrm{~g} / \mathrm{gCOD}$ for Run 1 and Run 2, respectively, which was in the similar level of

19 previous studies.(Brown et al., 2015) No further SCOD degradation was observed in

20 MFCs, confirming with previous findings that MFCs couldn't remove organics to a lower

21 level. However, the SCOD in the OMBR draw solution maintained below $20 \mathrm{mg} / \mathrm{L}$,

22 indicating very good rejection $(>90 \%)$ and organic removal $(>95 \%)$ by the TFC

23 membrane OMBR reactor, which guaranteed effluent quality. 


\section{[Figure 4]}

3 The changes of nutrients $\left(\mathrm{NH}_{3}-\mathrm{N}\right.$ and $\left.\mathrm{PO}_{4}-\mathrm{P}\right)$ in the OMBR bulk solution and draw

4 solution are shown in Figure 5 . With an inflow of $13.0 \pm 0.5 \mathrm{mg} / \mathrm{L}$, the OMBR showed

5 perfect rejection (> 99\%) of $\mathrm{PO}_{4}-\mathrm{P}$ (Figure $5 \mathrm{~b}$ ), leaving an accumulation of $\mathrm{PO}_{4}-\mathrm{P}$ in the

6 reactor and very low $\mathrm{PO}_{4}-\mathrm{P}$ in the DS. The concentration of $\mathrm{PO}_{4}-\mathrm{P}$ increased from 13.0

7 to $61.6 \pm 9.5$ and $119 \pm 19 \mathrm{mg} / \mathrm{L}$ for Run 1 and Run 2 in 8 days, respectively. The high

8 rejection of $\mathrm{PO}_{4}-\mathrm{P}$ is believed due to the electro-repulsion by the negatively charged

9 TFC membrane surface. Moreover, the reverse salt flux of $\mathrm{Na}^{+}(0.36 \mathrm{~nm})$ and $\mathrm{Cl}^{-}(0.33$

$10 \mathrm{~nm})$ could block the membrane pores $(0.42 \mathrm{~nm})$ thus hinder the forward diffusion of $\mathrm{PO}_{4}$

11 as well.(Xie et al., 2014) However, it should be noted that the accumulation in the

12 bioreactor might contribute to membrane fouling since $\mathrm{PO}_{4}{ }^{3-}$ may react with $\mathrm{Ca}^{2+}$ to

13 form $\mathrm{Ca}_{3}\left(\mathrm{PO}_{4}\right)_{2}$ precipitation.(Gu et al., 2015) Therefore, $\mathrm{PO}_{4}-\mathrm{P}$ recovery from the

14 bioreactor is needed in future studies. (Lu and $\mathrm{He}, 2015)$

\section{[Figure 5]}

17 In contrast with almost perfect rejection of $\mathrm{PO}_{4}-\mathrm{P}$, TFC membrane showed poor 18 rejection of $\mathrm{NH}_{3}-\mathrm{N}$ (Figure 5a), which was likely due to membrane properties and 19 solution chemistry. The surface of TFC membrane is negatively charged due to 20 deprotonation of carboxylic groups.(Lu et al., 2014; Xue et al., 2015) In FO, water 21 passed through the membrane from low-salinity FS to high-salinity DS. In the 22 meanwhile, portions of draw solutes (i.e., $\mathrm{NaCl}$ ) could reverse diffuse from DS to FS 23 against the concentration gradient, while the feed solutes (i.e., $\mathrm{NH}_{4}{ }^{+}, \mathrm{K}^{+}$) may also 
1 forward diffuse to the DS. However, because more $\mathrm{Na}^{+}$diffuses to $\mathrm{FS}$ than $\mathrm{Cl}^{-}$, (Coday

2 et al., 2013) a charge inequivalence in DS can be formed.(Lu et al., 2014) To maintain

3 charge neutrality, cations from FS may be exchanged to the DS side through the

4 negatively charged TFC membrane. As a highly diffusive cation, $\mathrm{NH}_{4}{ }^{+}$is likely be the

5 one balancing the charge (Figure S7 in Supporting Information), resulting lower

6 rejection level.(Xue et al., 2015) Moreover, since the $\mathrm{NH}_{4}{ }^{+} / \mathrm{NH}_{3}$ distribution is affected by

7 the solution $\mathrm{pH}$, more $\mathrm{NH}_{3}-\mathrm{N}$ was in the form of $\mathrm{NH}_{3}$ under high $\mathrm{pH}(>8.0$, Figure $\mathrm{S} 4$ in

8 Supporting Information), leading to higher flux of $\mathrm{NH}_{3}-\mathrm{N}$ toward the draw solution. To

9 reduce $\mathrm{NH}_{3}-\mathrm{N}$ permeation, draw solutes with higher diffusive anion but lower diffusive

10 cation may be a better choice than $\mathrm{NaCl}$, such as $\mathrm{MgCl}_{2}$.(Devia et al., 2015) Also,

11 nitrogen removal in bulk solution may be applied using nitrification and denitrification

12 and/or annomox processes,( $\mathrm{Li}$ et al., 2015) and alkalinity management may be

13 introduced into the OMBR system to remove $\mathrm{NH}_{3}-\mathrm{N}$ from the bioreactor. (Lu and He, 14 2015)

\subsection{Implications and Perspectives}

17 While this study demonstrates the feasibility and benefits of connecting MFCs with

18 OMBRs, many more works are required to optimize the performance of the individual

19 reactors and/or combined MFC-OMBR systems. Fouling mitigation strategies need to

20 be further developed for the TFC membranes, and the poor rejection of $\mathrm{NH}_{3}-\mathrm{N}$ needs to

21 be addressed.(Lu et al., 2014; Xue et al., 2015) Novel TFC membranes with lower

22 fouling and better $\mathrm{NH}_{3}-\mathrm{N}$ rejection (e.g, surface modifications) (Lu et al., 2014) should

23 be developed, and better draw solutes can be used.(Devia et al., 2015) Future studies

24 may also consider integrated nutrients and/or salts recovery. For example, MFCs in this 
1 study might be modified to microbial desalination cell (Luo et al., 2012a; Luo et al.,

2 2012b) or microbial recovery cell (Chen et al., 2015) to recover salts and nutrients from

3 the bioreactor. Operational optimizations can be investigated by modeling membrane

4 flux or hydraulic retention time (HRT), solute accumulation, and the recirculation ratio of

5 the MFC-OMBR system, all of which are key factors affecting membrane fouling,

6 treatment performance and energy production.

8 4. Conclusions

9 This study reveals synergy between MFCs and OMBRs for sustainable wastewater

10 treatment and energy production. The MFC-OMBR system effectively removed organics

11 and phosphorus at mesophilic condition, producing a high quality effluent, accompanied

12 with increased power production (up to $11.5 \mathrm{~W} / \mathrm{m}^{3}$ ) and less membrane fouling. The

13 MFCs were benefited from the accumulation of buffer capacity and solution conductivity

14 by the OMBR, leading to reduced internal resistance and increased power generation.

15 The pre-treatment from MFCs reduced membrane fouling for the OMBR, credit to low

16 sludge production ( $0.076 \pm 0.008 \mathrm{gTSS} / \mathrm{gCOD})$, low sludge load (<350 mg/L TSS), and

17 conditioned sludge property. While the study demonstrates the feasibility and potential,

18 more research is needed to improve nitrogen removal, reduce fouling, and optimize 19 system integration.

\section{Acknowledgements}

23 We appreciate the financial support from the Office of Naval Research 24 (N000141310901). The authors also thank to HTI for supplying membrane samples, Mr. 
1 Cole Sigmon from Boulder WWTP for providing sludge samples, and Dr. Zheng Ge for 2 valuable inputs in energy efficiency calculation.

3

4

5

6

7

8

9

10 
Aaron, D., Tsouris, C., Hamilton, C.Y., Borole, A.P., 2010. Assessment of the effects of flow rate and ionic strength on the performance of an air-cathode microbial fuel cell using electrochemical impedance spectroscopy. Energies 3(4), 592-606.

Achilli, A., Cath, T.Y., Marchand, E.A., Childress, A.E., 2009. The forward osmosis membrane bioreactor: a low fouling alternative to MBR processes. Desalination 239(1-3), 10-21.

APHA (1998) Standard ethods for the examination of water and wastewater, 20th Edition, APHA American Public Health Association.

Brown, R.K., Harnisch, F., Dockhorn, T., Schröder, U., 2015. Examining sludge production in bioelectrochemical systems treating domestic wastewater. Bioresource Technology 198, 913-917.

Cath, T.Y., Childress, A.E., Elimelech, M., 2006. Forward osmosis: principles, applications, and recent developments. Journal of Membrane Science 281(1-2), 70-87.

Chen, L., Gu, Y.S., Cao, C.Q., Zhang, J., Ng, J.W., Tang, C.Y., 2014. Performance of a submerged anaerobic membrane bioreactor with forward osmosis membrane for low-strength wastewater treatment. Water Research 50, 114-123.

Chen, X., Sun, D., Zhang, X., Liang, P., Huang, X., 2015. Novel self-driven microbial nutrient recovery cell with simultaneous wastewater purification. Scientific Reports 5, 15744.

Coday, B.D., Almaraz, N., Cath, T.Y., 2015. Forward osmosis desalination of oil and gas wastewater: impacts of membrane selection and operating conditions on process performance. Journal of Membrane Science 488, 40-55.

Coday, B.D., Heil, D.M., Xu, P., Cath, T.Y., 2013. Effects of transmembrane hydraulic pressure on performance of forward osmosis membranes. Environmental Science \& Technology 47(5), 2386-2393.

Devia, Y.P., Imai, T., Higuchi, T., Kanno, A., Yamamoto, K., Sekine, M., Van Le, T., 2015. Potential of magnesium chloride for nutrient rejection in forward osmosis. Journal of Water Resource and Protection 7(09), 730.

Ge, Z., Li, J., Xiao, L., Tong, Y.R., He, Z., 2014. Recovery of Electrical Energy in Microbial Fuel Cells. Environmental Science \& Technology Letters 1(2), 137-141.

Ge, Z., Ping, Q.Y., He, Z., 2013a. Hollow-fiber membrane bioelectrochemical reactor for domestic wastewater treatment. Journal of Chemical Technology and Biotechnology 88(8), 1584-1590.

Ge, Z., Ping, Q.Y., Xiao, L., He, Z., 2013b. Reducing effluent discharge and recovering bioenergy in an osmotic microbial fuel cell treating domestic wastewater. Desalination 312, 52-59.

Geise, G.M., Lee, H.S., Miller, D.J., Freeman, B.D., Mcgrath, J.E., Paul, D.R., 2010. Water purification by membranes: the role of polymer science. Journal of Polymer Science Part B-Polymer Physics 48(15), 1685-1718.

Gu, Y.S., Chen, L., Ng, J.W., Lee, C., Chang, V.W.C., Tang, C.Y.Y., 2015. Development of anaerobic osmotic membrane bioreactor for low-strength wastewater treatment at mesophilic condition. Journal of Membrane Science 490, 197-208.

Gu, Y.S., Wang, Y.N., Wei, J., Tang, C.Y.Y., 2013. Organic fouling of thin-film composite polyamide and cellulose triacetate forward osmosis membranes by oppositely charged macromolecules. Water Research 47(5), 1867-1874.

Holloway, R.W., Regnery, J., Nghiem, L.D., Cath, T.Y., 2014. Removal of trace organic chemicals and performance of a novel hybrid ultrafiltration-osmotic membrane bioreactor. Environmental Science \& Technology 48(18), 10859-10868.

Holloway, R.W., Wait, A.S., da Silva, A.F., Herron, J., Schutter, M.D., Lampi, K., Cath, T.Y., 2015. Long-term pilot scale investigation of novel hybrid ultrafiltration-osmotic membrane bioreactors. Desalination 363, 64-74.

Huggins, T., Fallgren, P., Jin, S., Ren, Z., 2013. Energy and performance comparison of microbial fuel cell and conventional aeration treating of wastewater. J Microb Biochem Technol S 6(2).

Lay, W.C.L., Liu, Y., Fane, A.G., 2010. Impacts of salinity on the performance of high retention membrane bioreactors for water reclamation: A review. Water Research 44(1), 21-40. 
Li, X., Lu, Y., He, Z., 2015. Removal of reverse-fluxed ammonium by anammox in a forward osmosis system using ammonium bicarbonate as a draw solute. Journal of Membrane Science 495, 424-430.

Liu, Y.L., Mi, B.X., 2012. Combined fouling of forward osmosis membranes: synergistic foulant interaction and direct observation of fouling layer formation. Journal of Membrane Science 407, 136144.

Logan, B.E., Wallack, M.J., Kim, K.Y., He, W.H., Feng, Y.J., Saikaly, P.E., 2015. Assessment of microbial fuel cell configurations and power densities. Environmental Science \& Technology Letters 2(8), 206-214.

Lu, L., Huang, Z., Rau, G.H., Ren, Z.J., 2015. Microbial electrolytic carbon capture for carbon negative and energy positive wastewater treatment. Environmental Science \& Technology 49(13), 8193-8201.

Lu, X.L., Boo, C., Ma, J., Elimelech, M., 2014. Bidirectional diffusion of ammonium and sodium cations in forward osmosis: role of membrane active layer surface chemistry and charge. Environmental Science \& Technology 48(24), 14369-14376.

Lu, Y.B., He, Z., 2015. Mitigation of salinity buildup and recovery of wasted salts in a hybrid osmotic membrane bioreactor-electrodialysis system. Environmental Science \& Technology 49(17), 1052910535.

Luo, H.P., Xu, P., Ren, Z.Y., 2012a. Long-term performance and characterization of microbial desalination cells in treating domestic wastewater. Bioresource Technology 120, 187-193.

Luo, H.P., Xu, P., Roane, T.M., Jenkins, P.E., Ren, Z.Y., 2012b. Microbial desalination cells for improved performance in wastewater treatment, electricity production, and desalination. Bioresource Technology 105, 60-66.

Mi, B., Elimelech, M., 2008. Chemical and physical aspects of organic fouling of forward osmosis membranes. Journal of Membrane Science 320(1-2), 292-302.

Mi, B.X., Elimelech, M., 2010. Gypsum scaling and cleaning in forward osmosis: measurements and mechanisms. Environmental Science \& Technology 44(6), 2022-2028.

Nam, J.Y., Kim, H.W., Lim, K.H., Shin, H.S., Logan, B.E., 2010. Variation of power generation at different buffer types and conductivities in single chamber microbial fuel cells. Biosensors \& Bioelectronics 25(5), 1155-1159.

Phillip, W.A., Yong, J.S., Elimelech, M., 2010. Reverse draw solute permeation in forward osmosis: modeling and experiments. Environmental Science \& Technology 44(13), 5170-5176.

Ren, L.J., Ahn, Y., Logan, B.E., 2014. A two-stage microbial fuel cell and anaerobic fluidized bed membrane bioreactor (MFC-AFMBR) system for effective domestic wastewater treatment. Environmental Science \& Technology 48(7), 4199-4206.

She, Q., Jin, X., Tang, C.Y., 2012. Osmotic power production from salinity gradient resource by pressure retarded osmosis: effects of operating conditions and reverse solute diffusion. Journal of Membrane Science 401-402, 262-273.

She, Q.H., Hou, D.X., Liu, J.X., Tan, K.H., Tang, C.Y.Y., 2013a. Effect of feed spacer induced membrane deformation on the performance of pressure retarded osmosis (PRO): implications for PRO process operation. Journal of Membrane Science 445, 170-182.

She, Q.H., Wong, Y.K.W., Zhao, S.F., Tang, C.Y.Y., 2013b. Organic fouling in pressure retarded osmosis: experiments, mechanisms and implications. Journal of Membrane Science 428(0), 181-189.

Su, X.Y., Tian, Y., Sun, Z.C., Lu, Y.B., Li, Z.P., 2013. Performance of a combined system of microbial fuel cell and membrane bioreactor: Wastewater treatment, sludge reduction, energy recovery and membrane fouling. Biosensors \& Bioelectronics 49, 92-98.

Tang, C.Y., She, Q., Lay, W.C.L., Wang, R., Fane, A.G., 2010. Coupled effects of internal concentration polarization and fouling on flux behavior of forward osmosis membranes during humic acid filtration. Journal of Membrane Science 354(1-2), 123-133.

Tian, Y., Ji, C., Wang, K., Le-Clech, P., 2014. Assessment of an anaerobic membrane bioelectrochemical reactor (AnMBER) for wastewater treatment and energy recovery. Journal of Membrane Science 450, 242-248. 
Vrijenhoek, E.M., Hong, S., Elimelech, M., 2001. Influence of membrane surface properties on initial rate of colloidal fouling of reverse osmosis and nanofiltration membranes. Journal of Membrane Science 188(1), 115-128.

Wang, H.M., Park, J.D., Ren, Z.Y., 2012. Active energy harvesting from microbial fuel cells at the maximum power point without using resistors. Environmental Science \& Technology 46(9), 52475252.

Wang, H.M., Ren, Z.Y.J., 2013. A comprehensive review of microbial electrochemical systems as a platform technology. Biotechnology Advances 31(8), 1796-1807.

Wang, Y.-N., Järvelä, E., Wei, J., Zhang, M., Kyllönen, H., Wang, R., Tang, C.Y., 2016. Gypsum scaling and membrane integrity of osmotically driven membranes: the effect of membrane materials and operating conditions. Desalination 377, 1-10.

Wang, Y.K., Sheng, G.P., Li, W.W., Huang, Y.X., Yu, Y.Y., Zeng, R.J., Yu, H.Q., 2011. Development of a novel bioelectrochemical membrane reactor for wastewater treatment. Environmental Science \& Technology 45(21), 9256-9261.

Wang, Z.W., Tang, J.X., Zhu, C.W., Dong, Y., Wang, Q.Y., Wu, Z.C., 2015. Chemical cleaning protocols for thin film composite (TFC) polyamide forward osmosis membranes used for municipal wastewater treatment. Journal of Membrane Science 475, 184-192.

Wei, J., Qiu, C.Q., Tang, C.Y.Y., Wang, R., Fane, A.G., 2011. Synthesis and characterization of flat-sheet thin film composite forward osmosis membranes. Journal of Membrane Science 372(1-2), 292-302.

Xiao, D., Tang, C.Y., Zhang, J., Lay, W.C.L., Wang, R., Fane, A.G., 2011. Modeling salt accumulation in osmotic membrane bioreactors: implications for FO membrane selection and system operation. Journal of Membrane Science 366(1-2), 314-324.

Xie, M., Nghiem, L.D., Price, W.E., Elimelech, M., 2014. Relating rejection of trace organic contaminants to membrane properties in forward osmosis: Measurements, modelling and implications. Water Research 49, 265-274.

Xue, W.C., Tobino, T., Nakajima, F., Yamamoto, K., 2015. Seawater-driven forward osmosis for enriching nitrogen and phosphorous in treated municipal wastewater: Effect of membrane properties and feed solution chemistry. Water Research 69, 120-130.

Yip, N.Y., Tiraferri, A., Phillip, W.A., Schiffman, J.D., Elimelech, M., 2010. High performance thin-film composite forward osmosis membrane. Environmental Science \& Technology 44(10), 3812-3818.

Yuan, H.Y., He, Z., 2015. Integrating membrane filtration into bioelectrochemical systems as next generation energy-efficient wastewater treatment technologies for water reclamation: A review. Bioresource Technology 195, 202-209.

Zhang, F., Brastad, K.S., He, Z., 2011. Integrating forward osmosis into microbial fuel cells for wastewater treatment, water extraction and bioelectricity generation. Environmental Science \& Technology 45(15), 6690-6696.

Zhang, M.M., Hou, D.X., She, Q.H., Tang, C.Y.Y., 2014. Gypsum scaling in pressure retarded osmosis: experiments, mechanisms and implications. Water Research 48, 387-395.

Zhang, X.Y., He, W.H., Ren, L.J., Stager, J., Evans, P.J., Logan, B.E., 2015. COD removal characteristics in air-cathode microbial fuel cells. Bioresource Technology 176, 23-31.

Zuo, K.C., Liang, S., Liang, P., Zhou, X.C., Sun, D.Y., Zhang, X.Y., Huang, X., 2015. Carbon filtration cathode in microbial fuel cell to enhance wastewater treatment. Bioresource Technology 185, 426-430. 


\section{List of Tables}

2 Table 1. Summary of operation conditions of the two-stage MFC-OMBR system; each 3 run was performed three cycles.

Table 1. Summary of operation conditions of the two-stage MFC-OMBR system; each run was performed three cycles.

\begin{tabular}{lllll}
\hline Name & $\begin{array}{l}\text { Operation } \\
\text { regime }\end{array}$ & $\begin{array}{l}\text { Sludge Dose } \\
\text { (mg TSS/L) }\end{array}$ & $\begin{array}{l}\text { Membrane } \\
\text { Cleaning }\end{array}$ & Condition \\
\hline Run 1 & MFC-OMBR & - & after run & Anaerobic \\
Run 2 & MFC-OMBR & - & daily & Anaerobic \\
Run 3 & MFC-OMBR & 2000 & after run & Anaerobic \\
Run 4 & OMBR & 2000 & after run & Anaerobic \\
\hline
\end{tabular}




\section{List of Figures}

Figure 1. Schematic diagram of the two-stage MFC-OMBR system.

Figure 2. Time-course changes of (a) electrical conductivity in the OMBR and (b) membrane flux during Run 1-4. Run 1: no sludge dose and without daily membrane cleaning; Run 2: no sludge dose and with daily membrane cleaning; Run 3: 2000 $\mathrm{mgTSS} / \mathrm{L}$ anaerobic sludge in MFC and without daily membrane cleaning; Run 4: no MFC with $2000 \mathrm{mgTSS} / \mathrm{L}$ anaerobic sludge and without daily membrane cleaning; Modeling: simulation without considering membrane fouling. The error bars represent the standard deviations based on three independent experiments.

Figure 3. Maximum power production from the MFCs during Run 1 and Run 2. Run 1: no sludge dose and without daily membrane cleaning; Run 2: no sludge dose and with daily membrane cleaning. The error bars represent the standard deviations based on three independent experiments.

Figure 4. Time-course changes of SCOD concentrations in the MFC effluent, OMBR bulk solution, and draw solution, as well as the COD removal during Run 1. Run 1: no sludge dose and without daily membrane cleaning. The error bars represent the standard deviations based on three independent experiments.

Figure 5. Time-course changes of (a) $\mathrm{NH}_{3}-\mathrm{N}$ and (b) $\mathrm{PO}_{4}-\mathrm{P}$ concentrations in the OMBR bulk and draw solution during Run 1 and Run 2. Run 1: no sludge dose and without daily membrane cleaning; Run 2: no sludge dose and with daily membrane cleaning. The error bars represent the standard deviations based on three independent experiments. 


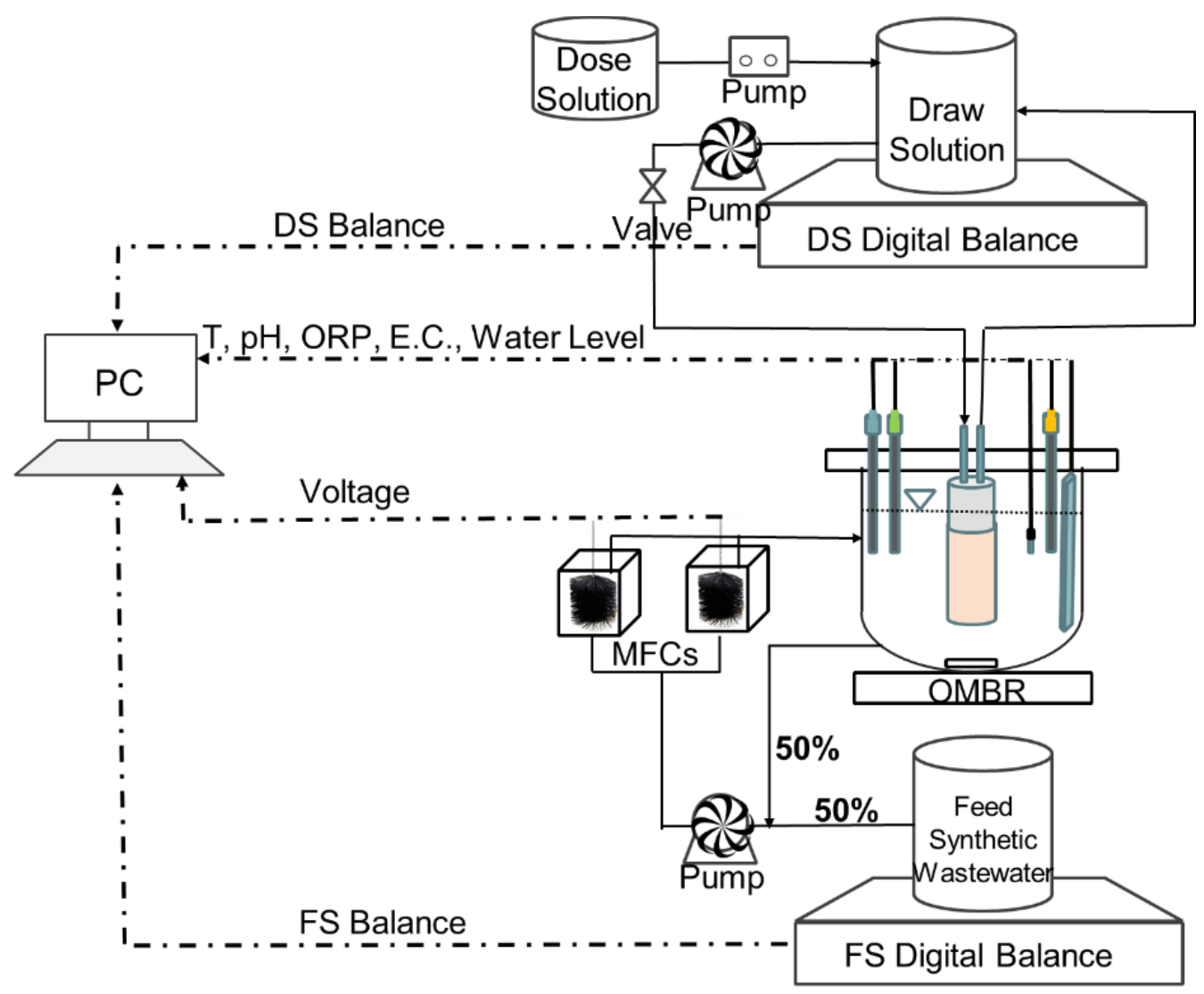

Figure 1. Schematic diagram of the two-stage MFC-OMBR system. 
4

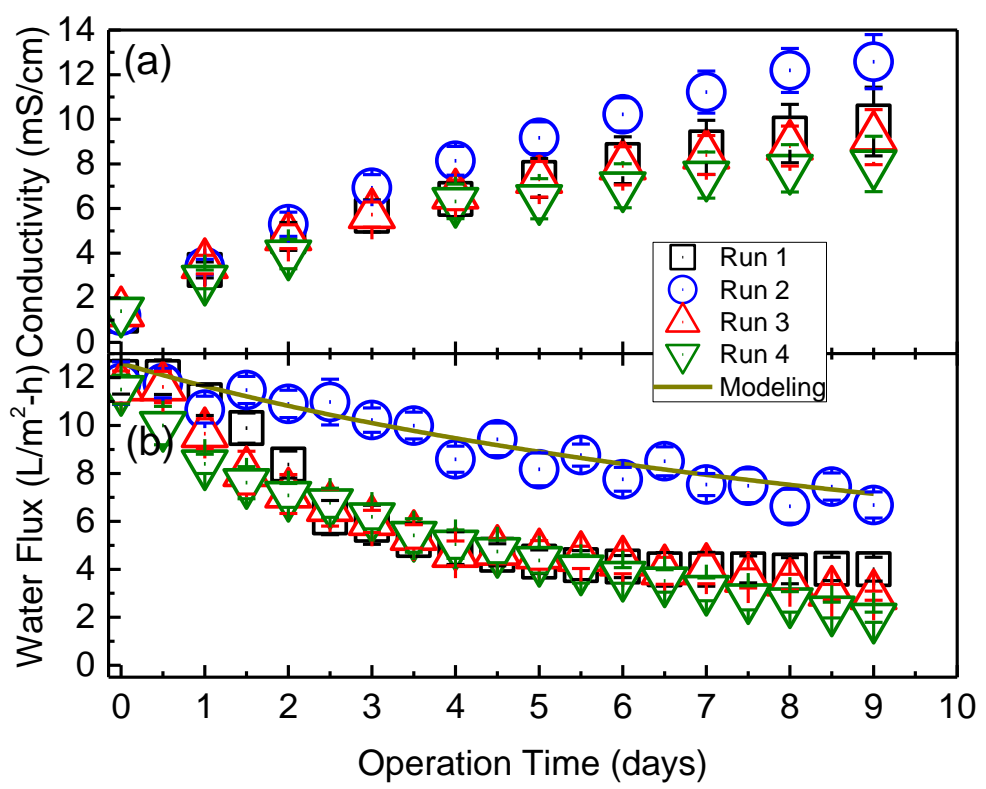

Figure 2. Time-course changes of (a) electrical conductivity in the OMBR and (b) membrane flux during Run 1-4. Run 1: no sludge dose and without daily membrane cleaning; Run 2: no sludge dose and with daily membrane cleaning; Run 3: $2000 \mathrm{mgTSS} / \mathrm{L}$ anaerobic sludge in MFC and without daily membrane cleaning; Run 4: no MFC with $2000 \mathrm{mgTSS} / \mathrm{L}$ anaerobic sludge and without daily membrane cleaning; Modeling: simulation without considering membrane fouling. The error bars represent the standard deviations based on three independent experiments. 


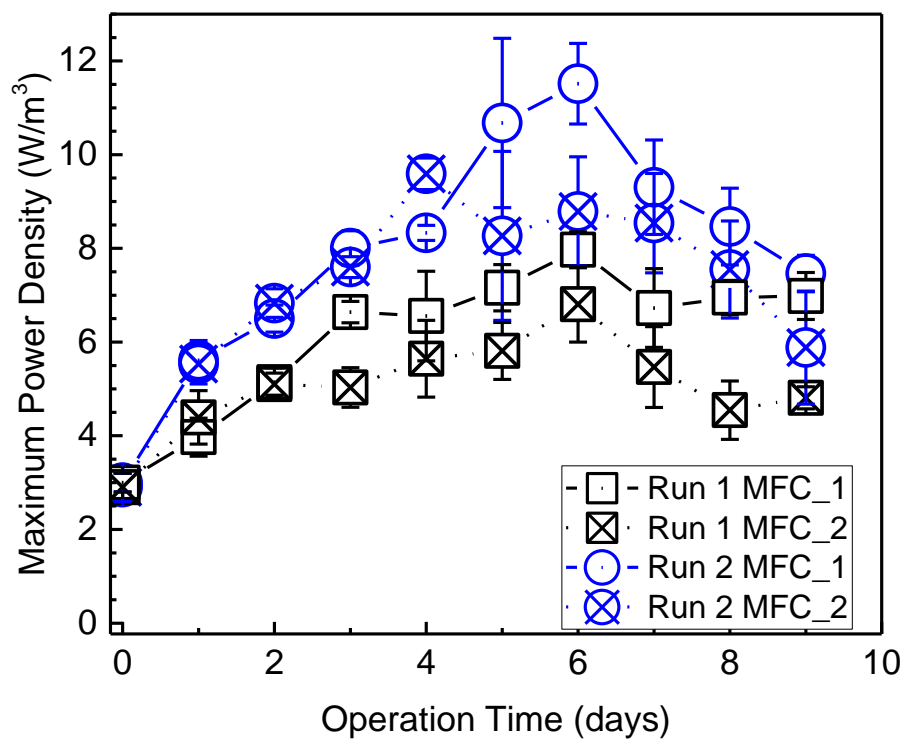

Figure 3. Maximum power production from the MFCs during Run 1 and Run 2. Run 1: no sludge dose and without daily membrane cleaning; Run 2: no sludge dose and with daily membrane cleaning. The error bars represent the standard deviations based on three independent experiments. 


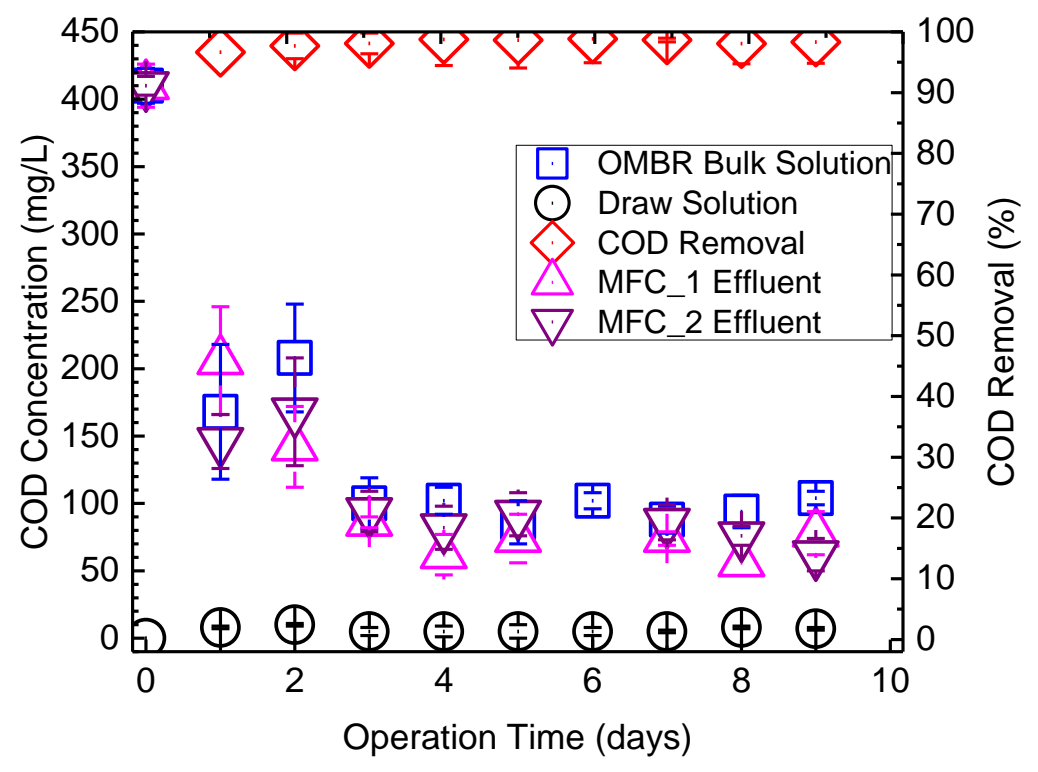

Figure 4. Time-course changes of SCOD concentrations in the MFC effluent, OMBR bulk solution, and draw solution, as well as the COD removal during Run 1. Run 1: no sludge dose without daily membrane cleaning. The error bars represent the standard deviations based on three independent experiments. 


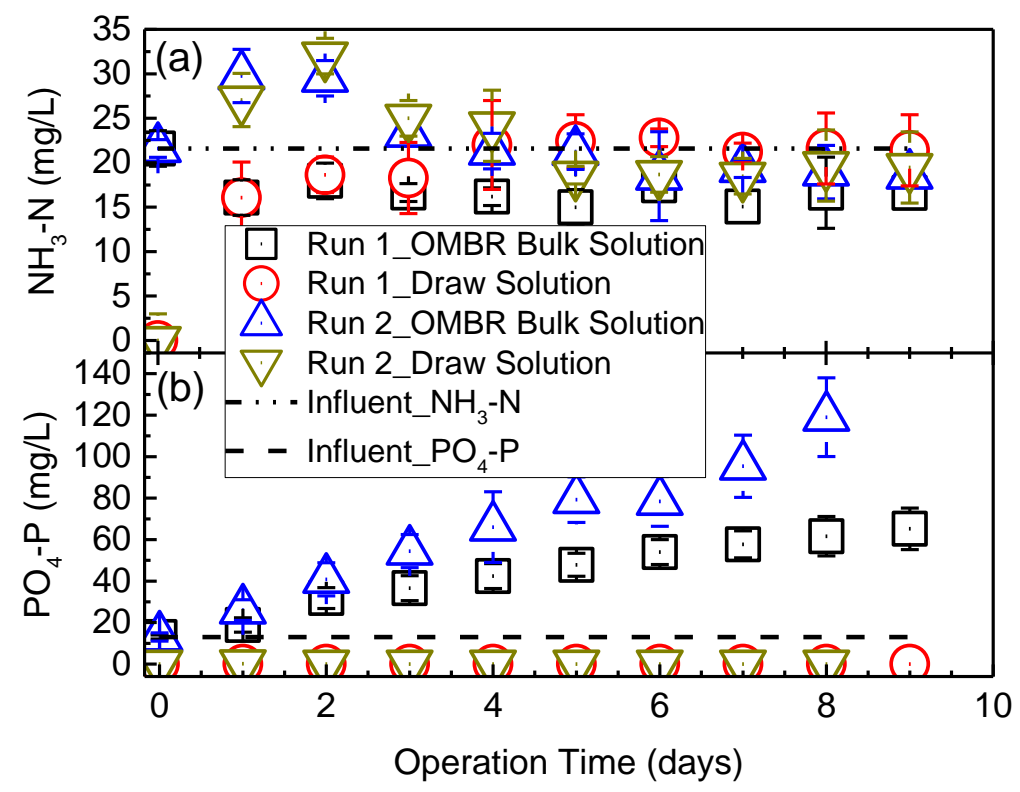

Figure 5. Time-course changes of (a) $\mathrm{NH}_{3}-\mathrm{N}$ and (b) $\mathrm{PO}_{4}-\mathrm{P}$ concentrations in the OMBR bulk and draw solution during Run 1 and Run 2. Run 1: no sludge dose and without daily membrane cleaning; Run 2: no sludge dose and with daily membrane cleaning. The error bars represent the standard deviations based on three independent experiments. 


\section{Graphical Abstract}
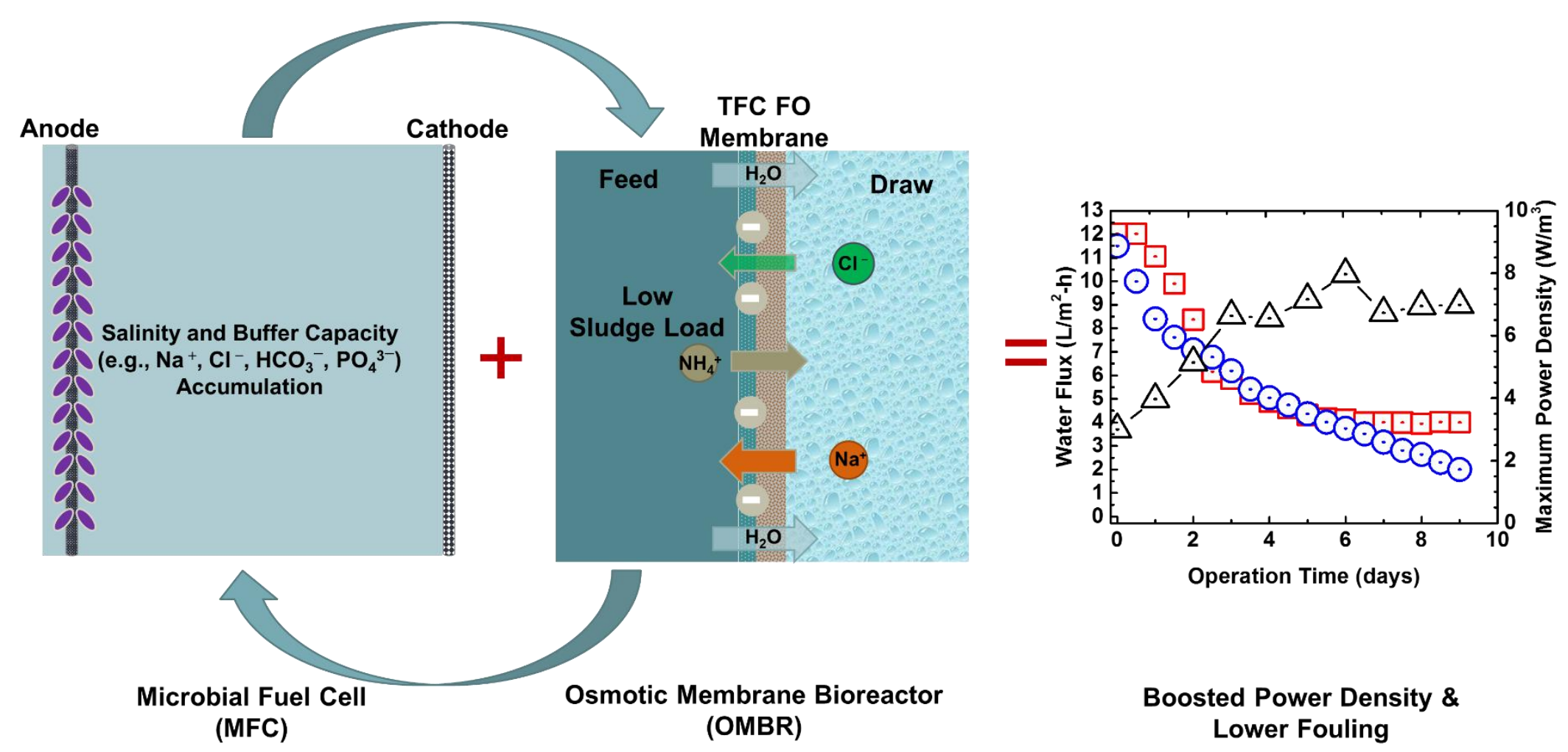

Boosted Power Density \& Lower Fouling 